\title{
Safety, Pharmacokinetics, and Anti-inflammatory Effects of Intratracheal Recombinant Human Clara Cell Protein in Premature Infants with Respiratory Distress Syndrome
}

\author{
CAROLYN R. LEVINE, IRA H. GEWOLB, KRISTEN ALLEN, RICHARD W. WELCH, \\ JAMES M. MELBY, SIMCHA POLLACK, THOMAS SHAFFER, APRILE L. PILON, AND \\ JONATHAN M. DAVIS
}

CardioPulmonary Research Institute and the Departments of Pediatrics [C.R.L., J.M.D., K.A.] and Biostatistics [S.P.], Winthrop-University Hospital, SUNY Stony Brook School of Medicine, Mineola, New York 11501; St. Johns University [S.P.], Jamaica, New York 11439; University of Maryland School of Medicine [I.H.G.], Baltimore, Maryland 21201; Temple University School of Medicine [T.S.], Philadelphia, Pennsylvania 19140; and Claragen, Inc. [R.W.W., J.M.M., A.L.P.], College Park, Maryland 20742

\begin{abstract}
Clara cell $10-\mathrm{kD}$ protein $(\mathrm{CC} 10)$ is a potent anti-inflammatory protein that is normally abundant in the respiratory tract. CC10 is deficient and oxidized in premature infants with poor clinical outcome (death or the development of bronchopulmonary dysplasia). The safety, pharmacokinetics, and anti-inflammatory activity of recombinant human CC10 (rhCC10) were evaluated in a randomized, placebo-controlled, doubleblinded, multicenter trial in premature infants with respiratory distress syndrome. A total of 22 infants (mean birth weight: $932 \mathrm{~g}$; gestational age: $26.9 \mathrm{wk})$ received one intratracheal dose of placebo $(n=7)$ or 1.5 $\mathrm{mg} / \mathrm{kg}(n=8)$ or $5 \mathrm{mg} / \mathrm{kg}(n=7)$ rhCC10 within $4 \mathrm{~h}$ of surfactant treatment. Pharmacokinetic analyses demonstrated that the serum halflife was 11.6 (1.5 mg/kg group) and $9.9 \mathrm{~h} \mathrm{(5} \mathrm{mg/kg} \mathrm{group).} \mathrm{Excess}$ circulating CC10 was eliminated via the urine within $48 \mathrm{~h}$. rhCC10treated infants showed significant reductions in total cell count $(p<$ $0.0002)$, neutrophil counts $(p<0.001)$, and total protein concentrations $(p<0.01)$ and tended to have decreased IL-6 $(p<0.07)$ in tracheal aspirate fluid collected over the first $3 \mathrm{~d}$ of life. Infants in all three groups showed comparable growth. At 36 wk postmenstrual age, five of seven infants were still hospitalized and two of seven infants were receiving oxygen in the placebo group compared with two of seven hospitalized and one of seven receiving oxygen in the $1.5-\mathrm{mg} / \mathrm{kg}$ group and four of six
\end{abstract}

\section{ABSTRACT}

hospitalized and three of six receiving oxygen in the $5-\mathrm{mg} / \mathrm{kg}$ group. A single intratracheal dose of rhCC10 was well tolerated and had significant anti-inflammatory effects in the lung. Multiple doses of rhCC10 will be investigated for efficacy in reducing pulmonary inflammation and ameliorating bronchopulmonary dysplasia in future studies. (Pediatr Res 58: 15-21, 2005)

BAL, bronchoalveolar lavage

BPD, bronchopulmonary dysplasia

CC10, Clara cell 10-kD protein

DSMC, data safety monitoring committee

IT, intratracheal

NCPAP, nasal continuous positive airway pressure

NEC, necrotizing enterocolitis

PMA, postmenstrual age

RDS, respiratory distress syndrome

rhCC10, recombinant human $\mathrm{CC} 10$

TAF, tracheal aspirate fluid
Bronchopulmonary dysplasia (BPD) affects 20-60\% of all premature, very low birth weight infants. It is associated with substantial morbidity and mortality as well as extremely high health care costs. Although the widespread use of exogenous surfactant and antenatal steroid therapy has reduced the overall severity of BPD, the prevalence of this condition has increased

Received April 14, 2004; accepted October 27, 2004.

Correspondence: Jonathan M. Davis, M.D., Department of Pediatrics, Winthrop University Hospital, SUNY Stony Brook School of Medicine, 259 First Street, Mineola, NY 11501; e-mail: jdavis@winthrop.org.

Supported by National Heart, Lung, and Blood Institute Grant HL66965-02 and sponsored by Claragen, Inc.

DOI: 10.1203/01.PDR.0000156371.89952.35 with improved survival of very low birth weight infants. BPD is a multifactorial disease process that is the end result of an immature, surfactant-deficient lung that has been exposed to hyperoxia, mechanical ventilation, and infection. These forces initiate a cascade of proinflammatory cytokines that lead to the development of significant inflammatory changes and chronic lung injury.

Clara cell $10-\mathrm{kD}$ protein $(\mathrm{CC} 10)$ is also known as uteroglobin. It is a small homodimeric secretory protein that is produced by mucosal epithelial cells (1). In humans, Clara cells are the main site of CC10 production (located in the airways), and several other organs synthesize smaller amounts of mRNA encoding this protein (2-4). CC10 also circulates in the blood 
and is excreted in urine $(5,6)$. It is thought to have numerous anti-inflammatory properties and to play a significant role in modulating innate immunity. CC10 inhibits secretory phospholipase $A_{2}(7,8)$, an enzyme that degrades surfactant and facilitates prostaglandin biosynthesis. In vitro, $\mathrm{CC} 10$ has been shown to inhibit neutrophil, monocyte, and fibroblast chemotaxis and suppress IL-2-stimulated release of tumor necrosis factor- $\alpha, \mathrm{IL}-1 \beta$, and interferon- $\gamma$ from human peripheral blood lymphocytes (9-11). In addition, CC10 inhibits the formation of the proinflammatory, fibronectin/IgA complex that may minimize fibrotic changes in the lung (12). In vivo evidence of these anti-inflammatory properties comes from studies of transgenic mice deficient in CC10. Exposure of these mice to 100\% oxygen results in earlier mortality as well as an exacerbated pulmonary inflammatory response (13). More recently, rhCC10 was shown to decrease inflammation and facilitate clearance of infection in a mouse model of pulmonary respiratory syncytial virus infection (14).

Very low concentrations of $\mathrm{CC} 10$ have been found in tracheal aspirate fluid (TAF) of ventilated premature infants relative to adult levels $(6,15)$. The appearance of $\mathrm{CC} 10$ in the amniotic fluid dates from $16 \mathrm{wk}$ of gestation and seems to increase as a function of gestational as well as postnatal age (16). CC10 concentrations in TAF of premature infants who were born at 28-32 wk of gestation has been found to be 2-4 orders of magnitude less than those found in the sputum of healthy adults $(6,15)$. CC10 concentrations have been demonstrated to correlate negatively with the concentration of inspired oxygen required by preterm infants with respiratory distress syndrome (RDS) (17). Most recently, Ramsey et al. (18) demonstrated that not only were CC10 concentrations lower in TAF from infants who either died or developed BPD, but also the limited amount of available CC10 was oxidized and demonstrated less immunoreactivity relative to controls.

It is the immune-modulating and anti-inflammatory properties of CC10 that make it a potential candidate for use in the prevention of BPD. We demonstrated previously that a single dose of intratracheal (IT) recombinant human CC10 (rhCC10), given at baseline to newborn piglets that were ventilated with $100 \%$ oxygen for $48 \mathrm{~h}$, was safe and well tolerated. In addition, it seemed to improve gas exchange and lung compliance while reducing some inflammatory mediators (19). A pharmacokinetic profile was also established, which led to the current Phase 1 multicenter, placebo-controlled, randomized trial to evaluate the safety and pharmacokinetics of rhCC10 in ventilated preterm infants with RDS.

\section{METHODS}

Patients. Patients were enrolled in this placebo-controlled, blinded, doseranging study at four participating hospitals: the University of Maryland School of Medicine (Baltimore, MD); Mercy Medical Center (Baltimore, MD); Winthrop-University Hospital, SUNY Stony Brook School of Medicine (Mineola, NY); and Christiana HealthCare Systems (Wilmington, DE).

Newborn infants were eligible for randomization when the following criteria were met: 1) age $\leq 24 \mathrm{~h} ; 2$ ) birth weight between 700 and $1300 \mathrm{~g} ; 3$ ) gestational age $\geq 24 \mathrm{wk} ; 4$ ) diagnosis of RDS based on clinical and radiographic criteria; 5) requirement for intubation and mechanical ventilation; and ๑) receipt of surfactant, $100 \mathrm{mg} / \mathrm{kg}$ (Survanta; Ross Laboratory). Patients could be given subsequent doses of surfactant if clinically indicated after rhCC10 administration. Infants were not eligible for the study when any of the following were present: 1) major congenital abnormalities (chromosomal, cardiac, pulmonary, or renal); 2) evidence of perinatal asphyxia (defined as a cord $\mathrm{pH} \leq 7.00$ and/or an Apgar score of $<4$ at $10 \mathrm{~min}$ ); 3) evidence of sepsis (as defined by total leukocytes $<5000 / \mathrm{mm}^{3}$ and/or an absolute neutrophil count $<1000 / \mathrm{mm}^{3}$ and/or an immature to mature neutrophil ratio $\geq 0.4$ ); 4) enrollment in any other study involving administration of another investigational drug; 5) any other condition that, in the judgment of the attending physician, might increase the risk for adverse events.

The Institutional Review Boards at each site approved the study protocol and patient informed consent forms. Written informed consent was obtained from a parent or legal guardian for every patient enrolled in the study. An independent data safety monitoring committee (DSMC) that consisted of five members appointed by the National Heart, Lung, and Blood Institute monitored safety of the study on an ongoing basis. The DSMC received information on all adverse events and had authority to terminate enrollment in the study if deemed necessary. The randomization code for the study was provided to the DSMC for ongoing, unblinded evaluation of information on patients enrolled in the study.

Randomization. Patients were enrolled in two cohorts, each comparing study drug with placebo. The first cohort consisted of 12 patients, randomized so that one third $(n=4)$ received placebo and the other two thirds $(n=8)$ received $1.5 \mathrm{mg} / \mathrm{kg}$ of the study drug. After the first cohort of patients was enrolled and the safety data were reviewed by the DSMC, a second cohort of 12 patients could be potentially enrolled. They also were randomized so that one third $(n=4)$ received placebo and the other two thirds $(n=8)$ received $5.0 \mathrm{mg} / \mathrm{kg}$ of study drug.

Each of 24 randomization envelopes was labeled with the cohort (first or second) and the sequential number of the randomization envelope. All of the randomization envelopes were kept in the pharmacy at Winthrop-University Hospital, but each site had a supply of the study drug for formulation. When a site enrolled a patient in the study, the pharmacist at the enrolling site contacted Winthrop-University Hospital, where the next randomization envelope was opened and the patient was assigned to one of the three groups (placebo, $1.5 \mathrm{mg} / \mathrm{kg}$, or $5.0 \mathrm{mg} / \mathrm{kg}$ ). Using this information, the pharmacist at the enrolling site formulated the study drug in a volume of $2 \mathrm{~mL} / \mathrm{kg}$ sterile, unbuffered saline.

Study drug administration. Each patient then received a single dose of the study drug (or placebo) as soon as possible after surfactant replacement therapy but not longer than $4 \mathrm{~h}$ after surfactant. Study drug or placebo was administered IT in two equal aliquots via a premeasured feeding tube placed into the distal third of the endotracheal tube, with the patient in the right and then left lateral decubitus position and 30 degrees of Trendelenburg. We previously demonstrated improved distribution with this method of administration (20).

rhCC10 was produced in Escherichia coli bacteria according to published methods (21) and purified by a proprietary process (Claragen, Inc., College Park, MD). The protein for the study was provided as a $>98 \%$ pure solution of the human CC10 homodimer. The biologic activity of each batch was compared using a proprietary secretory phospholipase $\mathrm{A}_{2}$ inhibition assay.

Collection of blood, urine, and TAF. Blood $(0.3 \mathrm{~mL})$ was obtained for the measurement of serum concentration of CC10 before drug administration $(t=$ 0 , from umbilical cord blood) and at $6,12,24,36$, and $48 \mathrm{~h}$. Urine samples were obtained at $12,24,36$, and $48 \mathrm{~h}$. Each urine sample consisted of the total volume voided over the previous $12 \mathrm{~h}$.

TAF was obtained by instilling $1 \mathrm{~mL}$ of saline into the endotracheal tube and suctioning the fluid into a Leuken's trap. The catheter then was washed with an additional $1 \mathrm{~mL}$ of saline. In some cases, the first tracheal aspirate was obtained before surfactant administration (baseline). Subsequent TAF collections were obtained at $12,24,48$, and $72 \mathrm{~h}$. TAF was collected only when infants continued to require intubation and mechanical ventilation. The TAF was centrifuged at $300 \times g$ for $10 \mathrm{~min}$ to pellet the cells. The supernatant was removed and frozen at $-70^{\circ} \mathrm{C}$ for CC10 ELISA and ELISAs for pulmonary inflammatory markers (19). The cell pellet was resuspended, and cell counts were performed using a hemocytometer. Cell differentials were determined by cytocentrifugation and differential staining. Total protein was measured using the Pierce BCA technique, and a panel of cytokines (Multiplex Cytokine Analysis; Luminex Corp., Austin, TX) was measured in TAF from all three experimental groups at 0,24 , and $48 \mathrm{~h}$ of life.

Pharmacokinetics. A pharmacokinetic analysis was conducted on samples of TAF, serum, and urine samples using a competitive ELISA for human CC10 developed by the sponsor. The assay uses a single anti-human CC10 polyclonal antibody as a capture reagent. CC10 in the sample competes with a synthetic $\mathrm{CC} 10$-horseradish peroxidase conjugate for antibody binding sites in the plate wells. Thus, the signal decreases with increasing CC10 concentration in the sample. Samples were run in duplicate, and a standard curve was run for each set of assays using rhCC10 calibrators. The limit of detection is $5 \mathrm{ng} / \mathrm{mL}$, and the results were reproducible with coefficients of variation typically $<20 \%$. 
The assay does not seem to distinguish between native and recombinant $\mathrm{CC} 10$. Immunogenicity of the study drug was assessed by titration of anti-C10 antibodies in serum obtained at $28 \mathrm{~d}$ after administration.

Clinical indices of safety and tolerability. The safety and the tolerability of the study drug were assessed through 36 wk postmenstrual age (PMA) by comparing the incidence of adverse events in the treatment and placebo groups and with the historical incidence of the adverse events at each institution. These include apnea/bradycardia, culture-proven sepsis, patent ductus arteriosus, intraventricular hemorrhage, periventricular leukomalacia, necrotizing enterocolitis (NEC), and retinopathy of prematurity. In addition, a preliminary assessment of the efficacy of IT rhCC10 in decreasing the incidence of BPD was made on the basis of the following data: duration of mechanical ventilation, oxygen requirement at $28 \mathrm{~d}$ with an abnormal chest radiograph, oxygen requirement at 36 wk PMA, or date of discharge.

Growth parameters were assessed at birth, $28 \mathrm{~d}$ of age, and 36 wk PMA. Blood chemistries and liver function tests were evaluated at the onset of the study and on days 7 and 28 after administration. Complete blood counts and urinalyses were performed on enrollment; 24,48 , and $72 \mathrm{~h}$; and 7 and $28 \mathrm{~d}$ after administration. Cranial ultrasounds were performed upon randomization and were repeated at 7 and $28 \mathrm{~d}$ of life.

Statistical analysis. Concentrations of $\mathrm{CC} 10$ and analysis of inflammatory markers over time were examined by using mixed-model ANOVA to test the interaction of time and dose. Nonparametric testing was performed when unequal variance was detected. Sample characteristics, the incidence of complications, and clinical outcomes were analyzed by Fischer exact test for categorical variables or one-way ANOVA for continuous variables.

\section{RESULTS}

Patients. A total of 22 patients were enrolled in the study: seven in the placebo group, eight in the $1.5-\mathrm{mg} / \mathrm{kg}$ group, and seven in the $5.0-\mathrm{mg} / \mathrm{kg}$ group. There were two deaths in the study, one in each of the treatment groups, leaving 20 patients to be evaluated for clinical outcomes. Patient enrollment was stopped early because of a decreasing enrollment rate, and only 10 of the planned 12 patients were enrolled in the second cohort. There were no apparent differences among the groups at enrollment for gestational age, weight, sex, race, or Apgar scores (Table 1). There were no withdrawals from the protocol.

Pharmacokinetics. CC10 concentrations in TAF are reported for time points when there were at least three patient samples per group (Fig. 1). This allowed for analysis of TAF samples for all groups through day 3 of life. Samples were not obtained when surfactant had been administered recently or when the infant had been extubated. At $12 \mathrm{~h}$ of life, CC10 concentrations in TAF from infants who were treated with the study drug was significantly higher than the placebo group, but there was little difference between the two groups that received rhCC10. Over the first $3 \mathrm{~d}$ of life, CC10 concentrations in TAF from infants who received placebo generally increased, whereas $\mathrm{CC} 10$ levels in treated infants tended to remain constant $(1.5 \mathrm{mg} / \mathrm{kg})$ or decrease $(5 \mathrm{mg} / \mathrm{kg}$; NS).

Serum concentrations of $\mathrm{CC} 10$ were similar in all three groups before treatment (Fig. 2). Infants who received rhCC10 had substantially higher serum concentrations than infants who received placebo, and this varied in a dose-dependent manner.

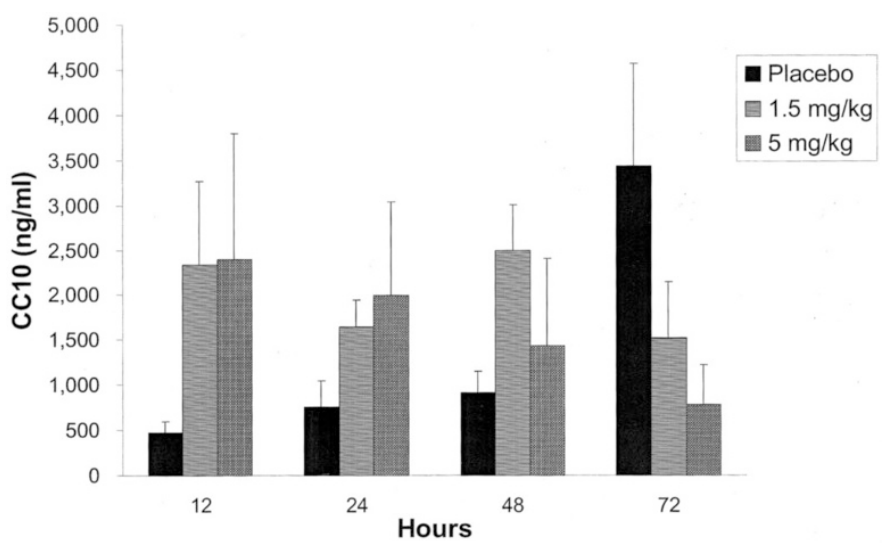

Figure 1. CC10 concentration (mean \pm SEM) in TAF. CC10 concentration in TAF of treated groups was significantly higher at $12 \mathrm{~h}$ than that of placebo control subjects. These values declined by $72 \mathrm{~h}$, whereas $\mathrm{CC} 10$ concentration in TAF of placebo control subjects tended to increase over the first $72 \mathrm{~h}$.

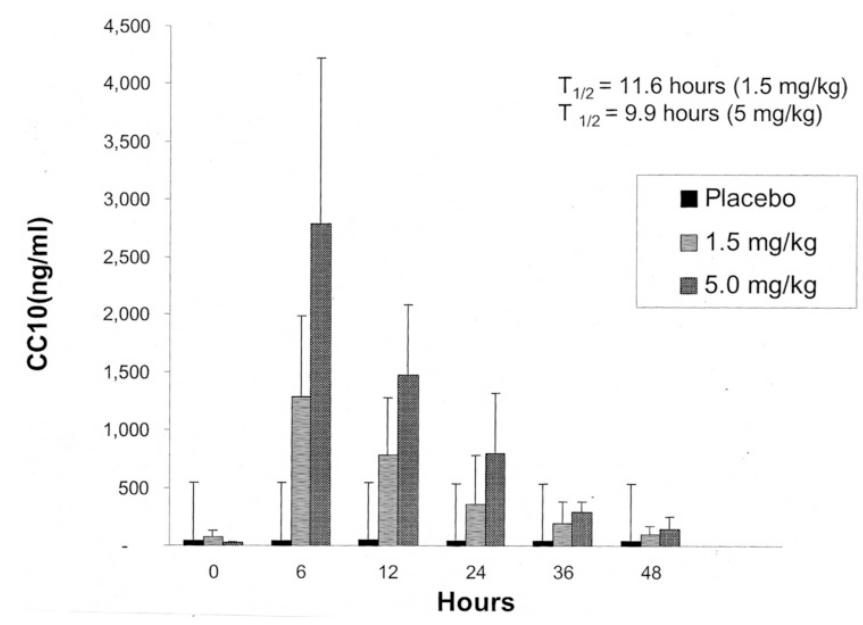

Figure 2. CC10 concentration in serum (mean \pm SEM). Serum concentrations of $\mathrm{CC} 10$ were similar in all groups at baseline. Infants who received $\mathrm{CC} 10$ had higher concentrations than infants in the placebo group, and this varied in a dose-dependent manner. Values were highest at $6 \mathrm{~h}$ in both treatment groups.

Average peak serum concentrations were $1289 \mathrm{ng} / \mathrm{mL}$ at 1.5 $\mathrm{mg} / \mathrm{kg}$ and $2794 \mathrm{ng} / \mathrm{mL}$ at $5.0 \mathrm{mg} / \mathrm{kg}$, which were $\sim 15-60$ times higher than normal serum levels in healthy adults. Average elimination half-lives were $11.6 \mathrm{~h}$ in the $1.5-\mathrm{mg} / \mathrm{kg}$ group and $9.9 \mathrm{~h}$ in the $5.0-\mathrm{mg} / \mathrm{kg}$ group, consistent with results from animal models (18).

In urine, $\mathrm{CC} 10$ concentrations in treated infants increased in a largely dose-dependent manner but were comparable to placebo levels within $48 \mathrm{~h}$ of administration (Fig. 3). This excretion pattern was similar to that observed in experimental animals that were given comparable IT doses of rhCC 10 .

Table 1. Study population

\begin{tabular}{|c|c|c|c|c|c|}
\hline & $\begin{array}{c}\text { Gestational age } \\
\text { (wk) }\end{array}$ & $\begin{array}{l}\text { Birth weight } \\
\text { (g) }\end{array}$ & $\begin{array}{c}\text { Sex } \\
\text { (male/total) }\end{array}$ & $\begin{array}{c}\text { Race } \\
\text { (white/black/ } \\
\text { Hispanic/Asian) }\end{array}$ & $\begin{array}{c}\text { Any maternal } \\
\text { steroids }\end{array}$ \\
\hline Placebo & $26.5 \pm 1.6$ & $943 \pm 137$ & $5 / 7(71 \%)$ & $3,2,1,1$ & $7 / 7$ \\
\hline $5.0 \mathrm{mg} / \mathrm{kg}$ & $26.5 \pm 1.2$ & $878 \pm 205$ & $3 / 6(50 \%)$ & $4,2,1,0$ & $6 / 6$ \\
\hline
\end{tabular}




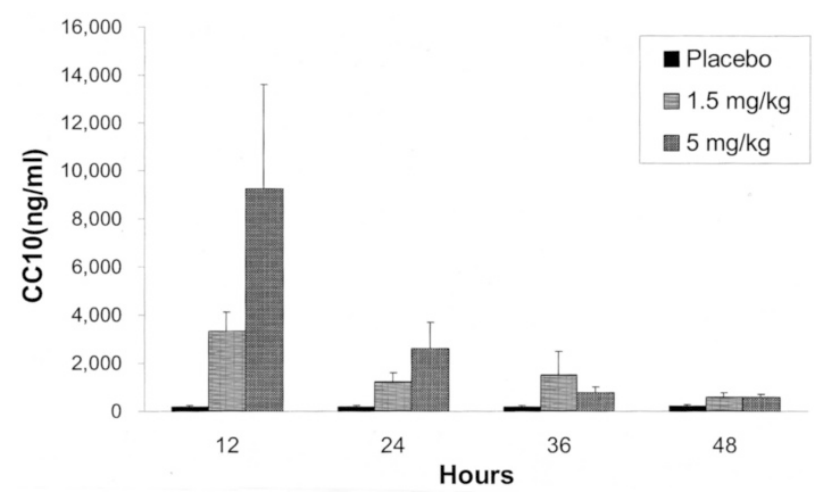

Figure 3. $\mathrm{CC} 10$ concentration in urine (mean \pm SEM). Urine concentrations of $\mathrm{CC} 10$ increased in a dose-dependent manner in the treated groups and were comparable to placebo levels within $48 \mathrm{~h}$ of administration.

An analysis of the potential immunogenicity of the study drug was conducted using serum samples that were collected on day 28 of life. Sera were tested for the presence of antiCC10 antibodies. No evidence of antibody formation was present in any of the 28-d sera from any of the groups.

Pulmonary inflammatory indices. Total cell and neutrophil counts were performed on TAF fluids and are shown in Figs. 4 and 5. Insufficient TAF samples were available from the 1.5$\mathrm{mg} / \mathrm{kg}$ group for proper statistical analysis and presentation (infants from this group were extubated relatively quickly). TAF recovery was at least $75 \%$ of the instilled volume. Total cell counts were significantly lower in the $5-\mathrm{mg} / \mathrm{kg}$ group on days 1-3 compared with the placebo group $(p<0.0002$, mixed model ANOVA; Fig. 4). Similarly, neutrophil counts were significantly lower in the $5-\mathrm{mg} / \mathrm{kg}$ group relative to controls $(p$ $<0.001$; Fig. 5). Total protein was significantly lower in TAF from both treatment groups compared with placebo $(p<0.01$; Fig. 6), suggesting that protein leak and macromolecular edema had been minimized.

A panel of cytokines (IL-1 $\beta$, IL-2, IL-6, IL-8, IL-10, interferon- $\gamma$, and tumor necrosis factor- $\alpha$ ) were measured in TAF from patients in all three groups at times 0,1 , and $2 \mathrm{~d}$ (with a minimum of three and maximum of seven samples per group).

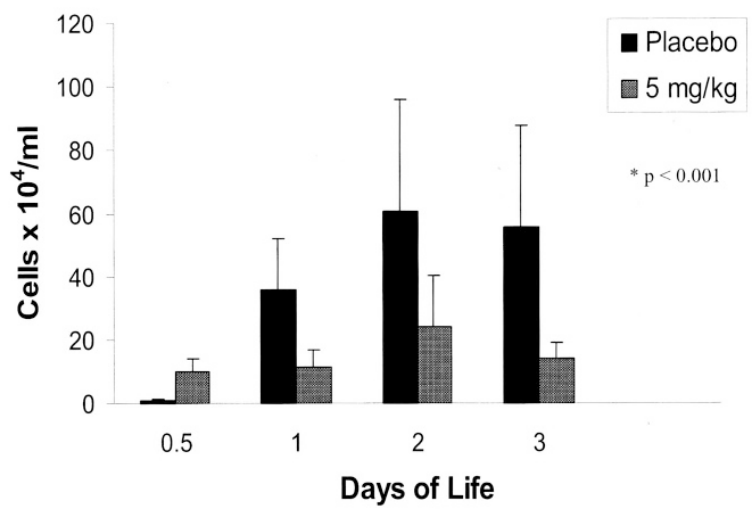

Figure 4. Effect of IT rhCC10 on TAF total cell counts in TAF. Total cell counts were significantly lower (mean \pm SEM) in animals that received 5 $\mathrm{mg} / \mathrm{kg}$ IT rhCC10 over the first $3 \mathrm{~d}$ of life ( $p<0.001$ ANOVA). Too few TAF samples $(n<3)$ were available from patients in the $1.5-\mathrm{mg} / \mathrm{kg}$ group to include in the analysis.

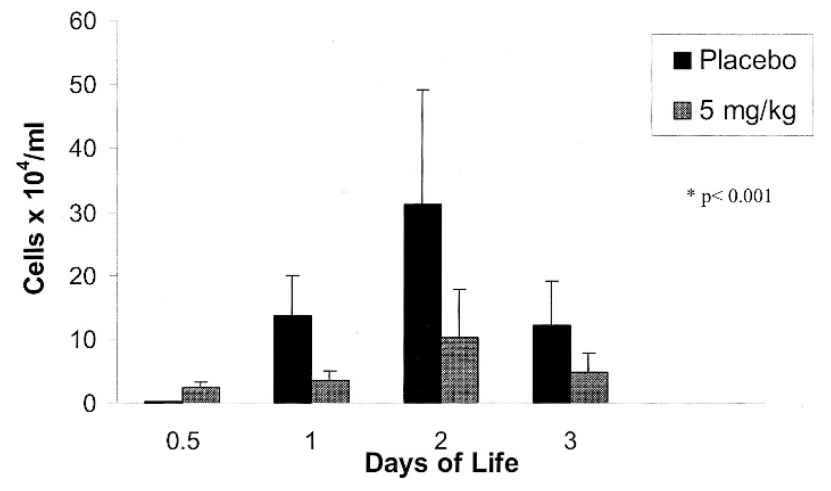

Figure 5. Effect of IT rhCC10 on total neutrophil counts in TAF. Total neutrophil counts were significantly lower (mean \pm SEM) in animals that received $5 \mathrm{mg} / \mathrm{kg}$ IT rhCC10 over the first $3 \mathrm{~d}$ of life ( $p<0.001$ ANOVA). Too few TAF samples were available from patients in the $1.5-\mathrm{mg} / \mathrm{kg}$ group $(n$ $<3$ ) to include in the analysis.

For all cytokines other than IL-6 and IL-8, concentrations were at or below the level of detection. IL- 6 concentrations tended to increase over time in the placebo group relative to both treatment groups $(p<0.07$; Fig. 7).

Clinical indices of safety and tolerability. There were no significant differences in the total number of days on mechanical ventilation [positive pressure ventilation and nasal continuous positive airway pressure (NCPAP); Table 2]. Patients in the low-dose rhCC10 group were on NCPAP for significantly fewer days than placebo control subjects $(p<0.05)$. When total days of mechanical ventilation were evaluated, there was still a tendency toward a reduction in the need for ventilatory support in this group $(p<0.07)$. Infants in the high-dose group $(5 \mathrm{mg} / \mathrm{kg}$ ) were mechanically ventilated longer than placebo control subjects $(p<0.05)$, but the overall number of days of ventilation and NCPAP were similar. In addition, there were no significant differences in the numbers of infants who were on oxygen and had abnormal radiographs at $28 \mathrm{~d}$.

At 36 wk PMA (two infants had died), only one (14\%) of seven patients in the low-dose group was still receiving oxygen compared with two (29\%) of seven infants in the placebo group and three $(50 \%)$ of six in the high-dose group (Fig. 8). In addition, only two (29\%) of seven patients in the low-dose

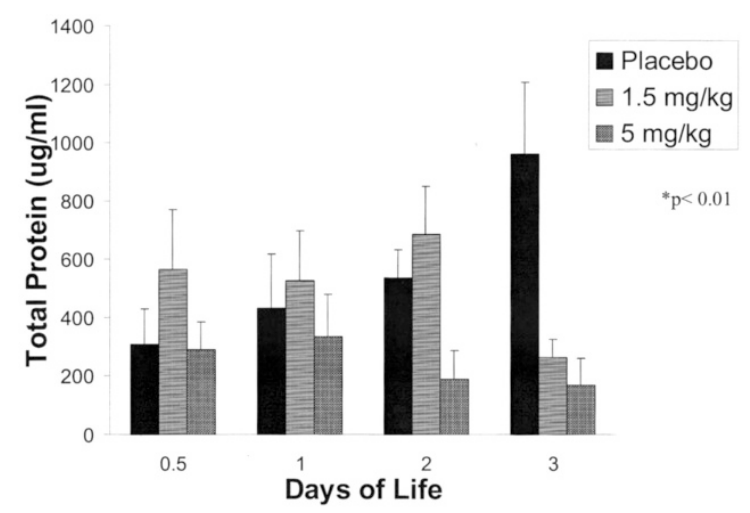

Figure 6. Effect of IT rhCC10 on total protein concentrations in TAF. Total protein was significantly lower in infants who received rhCC10 compared with control subjects $(p<0.01$, ANOVA). 


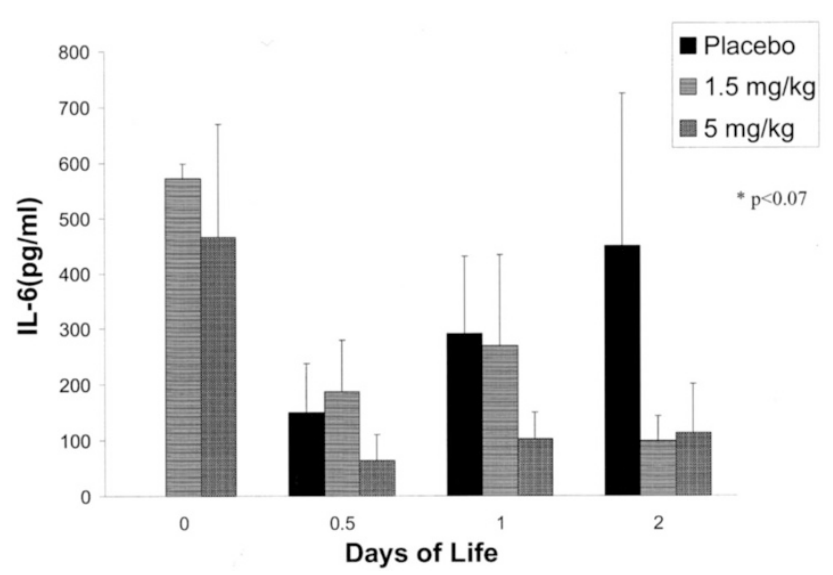

Figure 7. Effect of IT rhCC10 on IL-6 levels in TAF. IL-6 levels tended to be lower in animals that received rhCC10 ( $p<0.07$, ANOVA). No differences were seen in IL- 8 concentrations. Measurements for all other cytokines tested were at or below the limit of detection of the assay $(3 \mathrm{pg} / \mathrm{mL})$.

group were still hospitalized compared with five $(71 \%)$ of seven patients in the placebo group and four $(67 \%)$ of six in the high-dose groups. These differences, however, were not statistically significant. When total number of days on oxygen was analyzed, there were no differences among the groups (Table 2).

There were no significant differences in the incidence of nonrespiratory adverse events in the treatment and placebo groups (Table 2). Three cases of NEC occurred at one center in rhCC10-treated infants. However, other premature infants who were not enrolled in the study at that center also developed NEC at the same time. Growth parameters were similar among the groups. Similarly, there were no significant differences in values obtained for blood chemistries, complete blood counts, or results of urinalysis among groups at any of the time points evaluated.

Lack of immunogenicity and specific toxicity. There was no evidence of immunogenicity or specific toxicity of rhCC10. No difference in signal between 28-d sera from rhCC10-treated and placebo-treated infants was detected, indicating that antiCC10 antibodies were not present. In addition, there was no evidence of an increased incidence of bleeding, hemorrhage, or intraventricular hemorrhage as well as sepsis in rhCC10treated infants compared with placebo control subjects.

\section{DISCUSSION}

This study is the first to investigate the use of IT rhCC10 in preterm infants who are at risk for developing BPD. We demonstrated that rhCC10 seemed to reduce pulmonary inflammation, thus lending support for its use as a promising therapeutic agent. In addition, no significant concerns regarding safety or tolerability were noted.

The anti-inflammatory properties observed for rhCC10 in this study are consistent with those previously reported in various animal models of lung injury. The significant decreases in both total cell count and total neutrophil counts in the lung demonstrated in this study are consistent with the dosedependent inhibition of neutrophil chemotaxis in bronchoal- veolar lavage (BAL) fluid that was obtained from rhCC10treated newborn piglets that were ventilated for $48 \mathrm{~h}$ (19) as well as the inhibition of pulmonary neutrophil infiltration with rhCC10 treatment demonstrated in other animal models $(14,19,22,23)$. The significantly lower total protein concentration in TAF from human infants who were treated with rhCC10 is promising and is similar to the decreases in BAL protein concentration in ventilated newborn piglets that received rhCC10 (19). These results suggest a reduction in vascular permeability and protein leak in infants who are treated with rhCC10.

Several studies in premature infants have demonstrated that increased concentrations of cytokines and cells that are present in TAF within the first few days of life are associated with the subsequent development of BPD, suggesting an intimate role of inflammation in the pathogenesis of BPD $(24,25)$. Various animal studies have demonstrated that rhCC10-induced reduction in pulmonary neutrophil infiltration correlated with reduced cytokine formation (IL-8 in rabbits and lambs or MIP-2 in mice) as well as improved pulmonary histopathologic scores $(14,22)$. Given the limitations that small pilot studies present and the intrinsic biologic variability inherent in infants, we are encouraged that in our study there was a suggestion that rhCC10 reduced cytokine concentrations (IL-6) in TAF that was collected on days 2 and 3 .

An additional limitation of this study is the inability to obtain appropriate samples at later times as a result of patient dropout (extubation). Thus, it is difficult to come to significant conclusions in this small study about the time course of the anti-inflammatory effects of rhCC10. However, of the time points studied, the inhibition of cellular infiltrates was maximal on day 3. Similar timing was seen with respect to reductions in TAF total protein concentrations and proinflammatory cytokine levels in the infants.

The safety and pharmacokinetic data obtained in premature infants with RDS are consistent with observations from our previous study in ventilated newborn piglets (19). The rhCC10 was well tolerated after IT instillation in both the infants and the piglets (no major desaturation/bradycardic episodes), and pharmacokinetic profiles were also similar. The instilled rhCC10 was taken up into the circulation and cleared from the blood of the newborn piglets within $48 \mathrm{~h}$ of IT instillation, whereas a small percentage of the dose administered was detected in the BAL at $48 \mathrm{~h}$ after administration. This was also observed in infants, and the higher doses of rhCC10 showed shorter serum half-lives in both species, suggesting that CC10 in the circulation may be homeostatically regulated. The concentration of $\mathrm{CC} 10$ in urine directly correlated with the concentration of $\mathrm{CC} 10$ in serum, indicating that a substantial portion of the excess circulating $\mathrm{CC} 10$ is excreted via the kidneys, confirming the origin of urine protein-1 (6).

The CC10 concentration ([CC10]) in TAF varied with dose and decreased with time, except in the placebo group, in which an increase in endogenous [CC10] in TAF was noted on day 3 of life. Although there were no statistically significant differences between the placebo- and rhCC10-treated groups on days 2 and 3, the trends observed may be important. Whereas [CC10] in the TAF of the placebo group increased by day 3 , 
Table 2. Outcomes

\begin{tabular}{|c|c|c|c|c|}
\hline & Placebo & $1.5 \mathrm{mg} / \mathrm{kg}$ & $5 \mathrm{mg} / \mathrm{kg}$ & Significance \\
\hline Days on ventilator & $12 \pm 8.6$ & $8.6 \pm 8.3$ & $24 \pm 13.1^{*}$ & $* p<0.05$ vs placebo and $1.5 \mathrm{mg} / \mathrm{kg}$ \\
\hline Days on ventilator and NCPAP & $33 \pm 12.7$ & $18.6 \pm 14.2$ & $44.3 \pm 18.1$ & NS \\
\hline Days on $\mathrm{O}_{2}$ & $56.6 \pm 13$ & $49 \pm 5.6$ & $55 \pm 18$ & NS \\
\hline $\mathrm{O}_{2}$ at 36 wk PMA & $2 / 7$ & $1 / 7$ & $3 / 6$ & NS \\
\hline Hospitalized at 36 wk PCA & $5 / 7$ & $2 / 7$ & $4 / 6$ & NS \\
\hline Confirmed NEC & $0 / 7$ & $2 / 8$ & $1 / 7$ & NS \\
\hline Sepsis & $0 / 0$ & $1 / 8$ & $1 / 7$ & NS \\
\hline IVH & $2 / 7$ & $0 / 8$ & $1 / 7$ & NS \\
\hline PVL & $1 / 7$ & $0 / 8$ & $0 / 7$ & NS \\
\hline
\end{tabular}

PDA, patent ductus arteriosus; IVH, intraventricular hemorrhage; PVL, periventricular leukomalacia.

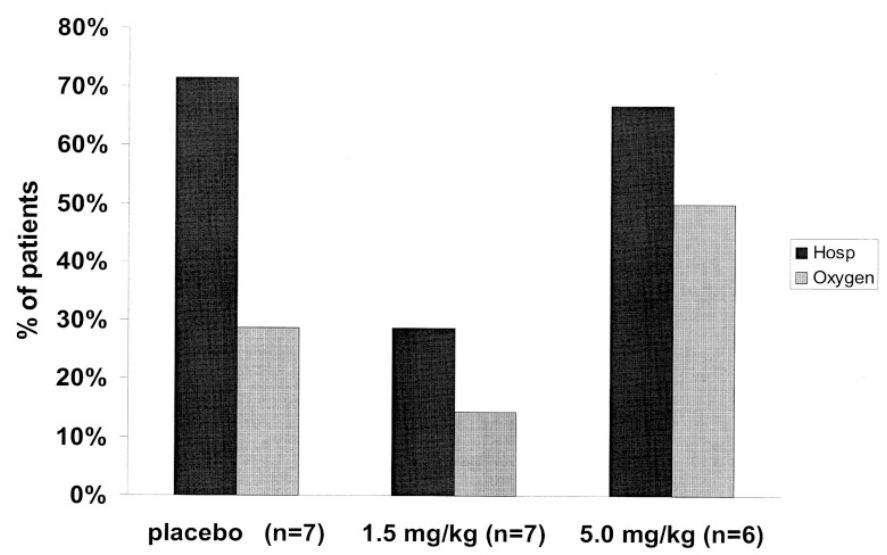

Figure 8. Comparison of percentage of patients who remained on oxygen at 36 wk PMA and percentage of patients who were hospitalized at 36 wk PMA in each treatment group.

[CC10] in the $1.5-\mathrm{mg} / \mathrm{kg}$ group remained fairly constant over the first $3 \mathrm{~d}$ of life, and the [CC10] in the $5-\mathrm{mg} / \mathrm{kg}$ group decreased between birth and day 3. The increase in CC10 in TAF in the placebo group indicates an increase in production of endogenous CC10. The decrease in the $5-\mathrm{mg} / \mathrm{kg}$ group by day 3 suggests that the instillation of the higher dose may have suppressed endogenous expression of $\mathrm{CC} 10$ in the lung epithelia. Feedback inhibition is a common mechanism for the regulation of expression of proteins. Further studies will address the duration of these effects.

rhCC10 administration did not seem to cause any significant safety issues in premature infants. In addition, IT rhCC10 did not elicit an immunogenic response from treated infants. The only adverse event that was increased in treated infants compared with placebo control subjects was NEC (NS), although it was difficult to attribute the NEC to the administration of rhCC10 for two reasons. First, excess CC10 was cleared from all infants by $48 \mathrm{~h}$ after administration and the three cases of confirmed NEC occurred 3-6 wk after administration. Second, all cases of confirmed NEC occurred at the same center. In addition, other cases of NEC occurred in this center in the same time frame in infants who were not enrolled in the rhCC10 study, suggesting a clustering of cases. Although it is unlikely that rhCC10 administration was related to the development of NEC, future studies will need to monitor this complication carefully.
There is some controversy that exists over the optimal method of comparing TAF data between groups; specifically, should directly measured values be presented, or should data be normalized using urea, secretory IgA, or total protein concentrations (to control for the effects of volume of TAF recovered; especially important when recovery volumes are quite variable)? We chose to continue with the interpretation of TAF data that we (and others) have published extensively in the past, because the recovery volume was at least $\geq 75 \%$ in all cases.

Previous publications related to the biologic activities of native rabbit uteroglobin and native human urine protein-1 suggest that CC10 may inhibit platelet aggregation and suppress the immune response in vivo $(11,26)$. However, there was no indication that rhCC10 mediated these activities in either newborn piglets or infants. Although specific platelet function testing was not performed, there was no increased incidence of bleeding or infectious complications in rhCC10-treated infants compared with the placebo group. This is consistent with an independent analysis of the effects of rhCC10 on the in vitro aggregation of human platelets (W. Jeske, unpublished data). Our results are further supported by a recent report demonstrating a beneficial effect of rhCC10 in a mouse model of respiratory syncytial virus infection (14).

As BPD continues to be a significant problem in the neonatal intensive care unit, new agents that can safely improve clinical pulmonary status are urgently needed. Agents such as recombinant human superoxide dismutase (27) and dexamethasone have been used in attempts to reduce inflammatory changes and lung injury. Whereas the prophylactic use of recombinant human superoxide dismutase has been shown to reduce pulmonary inflammation and improve long-term clinical status (27), dexamethasone has been shown to improve short-term pulmonary function but potentially worsen long-term pulmonary and neurologic outcome $(28,29)$. The reduction in inflammatory indices seen with rhCC10, in both animal models of lung injury and premature infants who are at risk for BPD, is comparable to that achieved with these agents. However, rhCC10 may be an even more attractive therapeutic agent given its effect on surfactant and phospholipase A2. Thus, in summary, rhCC10 demonstrated novel anti-inflammatory activities and a favorable safety profile in this small and preliminary phase I clinical trial. Future studies will involve varia- 
tions in dosing regimens (e.g. multiple doses) to maximize efficacy and hopefully prevent the development of BPD in high-risk premature infants.

Acknowledgments. We acknowledge the members of the DSMC (Chair: Heber Nielson, M.D., Billy Lou Short, M.D., Lynn T. Singer, M.D., Joel Frader, and Ralph O'Brien) and Dorothy Gail, Ph.D., and Mary Ann Berberich, Ph.D., of the National Heart, Lung, and Blood Institute for significant contributions to this study. In addition, we thank the Walter Reed Army Institute of Research, Biopilot Production Facility for the production of the GMP protein used in this study.

Aprile Pilon is an officer at Claragen, and Richard Welch and James Melby were employees of the company throughout the study.

\section{REFERENCES}

1. Mukherjee AB, Kundu GC, Mantile-Selvaggi G, Yuan CJ, Mandal AK, Chattopadhyay S, Zheng F, Pattabiraman N, Zhang Z 1999 Uteroglobin: a novel cytokine? Cell Mol Life Sci 55:771-787

2. Singh G, Singal S, Katyal SL, Brown WE, Gottron SA 1987 Isolation and amino acid composition of the isotypes of a rat Clara cell specific protein. Exp Lung Res 13:299-309

3. Peri A, Cordella-Miele E, Miele L, Mukherjee AB 1993 Tissue-specific expression of the gene coding for human Clara cell $10-\mathrm{kD}$ protein, a phospholipase A2-inhibitory protein. J Clin Invest 92:2099-2109

4. Rauch M, Loosfelt H, Philibert D, Milgrom E 1985 Mechanism of action of an antiprogesterone, RU486, in the rabbit endometrium. Effects of RU486 on the progesterone receptor and on the expression of the uteroglobin gene. Eur J Biochem 148:213-218

5. Kikukawa T, Mukherjee AB 1989 Detection of a uteroglobin-like phospholipase A2 inhibitory protein in the circulation of rabbits. Mol Cell Endocrinol 62:177-187

6. Bernard A, Roels H, Lauwerys R, Witters R, Gielens C, Soumillion A, Van Damme J, De Ley M 1992 Human urinary protein 1: evidence for identity with the Clara cell protein and occurrence in respiratory tract and urogenital secretions. Clin Chim Acta 207:239-249

7. Levin SW, Butler JD, Schumacher UK, Wightman PD, Mukherjee AB 1986 Uteroglobin inhibits phospholipase A2 activity. Life Sci 38:1813-1819

8. Mantile G, Miele L, Cordella-Miele E, Singh G, Katyal SL, Mukherjee AB 1993 Human Clara cell 10-kDa protein is the counterpart of rabbit uteroglobin. J Biol Chem 268:20343-20351

9. Vasanthakumar G, Manjunath R, Mukherjee AB, Warabi H, Schiffmann E 1988 Inhibition of phagocyte chemotaxis by uteroglobin, an inhibitor of blastocyst rejection. Biochem Pharmacol 37:389-394

10. Lesur O, Bernard A, Arsalane K, Lauwerys R, Begin R, Cantin A, Lane D 1995 Clara cell protein (CC-16) induces a phospholipase A2-mediated inhibition of fibroblast migration in vitro. Am J Respir Crit Care Med 152:290-297
11. Dierynck I, Bernard A, Roels H, De Ley M 1996 The human Clara cell protein biochemical and biological characterisation of a natural immunosuppressor. Mult Scler 1:385-387

12. Zheng F, Kundu GC, Zhang Z, Ward J, DeMayo F, Mukherjee AB 1999 Uteroglobin is essential in preventing immunoglobulin A nephropathy in mice. Nat Med 5:10181025

13. Johnston CJ, Mango GW, Finkelstein JN, Stripp BR 1997 Altered pulmonary response to hyperoxia in Clara cell secretory protein deficient mice. Am J Respir Cell Mol Biol 17:147-155

14. Wang SZ, Rosenberger CL, Bao YX, Stark JM, Harrod KS 2003 Clara cell secretory protein modulates lung inflammatory and immune responses to respiratory syncytial virus infection. J Immunol 171:1051-1060

15. Dhanireddy R, Lim M, Mukherjee A 1993 Uteroglobin-like protein levels in premature infants on long term ventilatory support. Pediatr Res 33:323A

16. Bernard A, Thielemans N, Lauwerys R, Langhendries JP, Van Lierde M, Freund MM 1994 Clara cell protein in human amniotic fluid: a potential marker of fetal lung growth. Pediatr Res 36:771-775

17. Lassus P, Nevalainen TJ, Eskola JU, Andersson S 2000 Clara-cell secretory protein in preterm infants' tracheal aspirates correlates with maturity and increases in infection. Pediatr Pulmonol 30:466-469

18. Ramsay PL, DeMayo FJ, Hegemier SE, Wearden ME, Smith CV, Welty SE 2001 Clara cell secretory protein oxidation and expression in premature infants who develop bronchopulmonary dysplasia. Am J Respir Crit Care Med 164:155-161

19. Chandra S, Davis JM, Drexler S, Kowalewska J, Chester D, Koo HC, Pollack S, Welch R, Pilon A, Levine CR 2003 Safety and efficacy of intratracheal recombinant human Clara cell protein in a newborn piglet model of acute lung injury. Pediatr Res 54:509-515

20. Langenback EG, Davis JM, Robbins C, Sahgal N, Perry RJ, Simon SR 1999 Improved pulmonary distribution of recombinant human $\mathrm{Cu} / \mathrm{Zn}$ superoxide dismutase, using a modified ultrasonic nebulizer. Pediatr Pulmonol 27:124-129

21. Mantile G, Fuchs C, Cordella-Miele E, Peri A, Mukherjee AB, Miele L 2000 Stable, long-term bacterial production of soluble, dimeric, disulfide-bonded protein pharmaceuticals without antibiotic selection. Biotechnol Prog 16:17-25

22. Nordby-Shashikant B, Miller TL, Melby J, Pilon AL, Shaffer TH, Wolfson MR 2003 Dose-response to rhCC10-augmented surfactant (SF) therapy in infant respiratory distress syndrome (RDS): inflammation and kinetic profiles. Pediatr Res 53:463A

23. Nordby-Shashikant B, Miller TL, Melby J, Pilon AL, Shaffer TH, Wolfson MR 1992 rhCC10-augmented surfactant (SF) therapy in acute lung injury (ALI): physiological and inflammatory profiles. Pediatr Res 51:469A

24. Bagchi A, Viscardi RM, Taciak V, Ensor JE, McCrea KA, Hasday JD 1994 Increased activity of interleukin-6 but not tumor necrosis factor-alpha in lung lavage of premature infants is associated with the development of bronchopulmonary dysplasia. Pediatr Res 36:244-252

25. Speer CP 2001 New insights into the pathogenesis of pulmonary inflammation in preterm infants. Biol Neonate 79:205-209

26. Manjunath R, Levin SW, Kumaroo KK, Butler JD, Donlon JA, Horne M, Fujita R, Schumacher UK, Mukherjee AB 1987 Inhibition of thrombin-induced platelet aggregation by uteroglobin. Biochem Pharmacol 36:741-746

27. Davis JM, Parad RB, Michele T, Allred E, Price A, Rosenfeld W; North American Recombinant Human CuZnSOD Study Group 2003 Pulmonary outcome at 1 year corrected age in premature infants treated at birth with recombinant human $\mathrm{CuZn}$ superoxide dismutase. Pediatrics 111:469-476

28. Barrington KJ 2001 The adverse neuro-developmental effects of postnatal steroids in the preterm infant: a systematic review of RCTs. BMC Pediatr 1:1

29. Yeh TF, Lin YJ, Huang CC, Chen JY, Lin CH, Lin HC, Hsieh WS, Lien YJ 1998 Early dexamethasone therapy in preterm infants: a follow-up study. Pediatrics 101:E7 